\title{
The Tumor-promoting Effects of FAM92A1-289 in Cervical Carcinoma Cells
}

\author{
HUI GUI ${ }^{1,2^{*}}$, XING-RONG GUO ${ }^{1,3 *}$, JUAN FANG $^{1}$, SHI-NAN MA ${ }^{1,3}$, GAO WU $^{2}$, JUN-HAO SHEN $^{1}$, \\ HAN-JUN TU ${ }^{1}$, DONG-SHENG LI ${ }^{1,3}$, LONG-JUN DAI $^{2,4}$ and XU-ZHI RUAN ${ }^{1,3}$ \\ ${ }^{1}$ College of Basic Medicine, Hubei University of Medicine, Shiyan, P.R. China; \\ ${ }^{2}$ Department of Neurosurgery, Taihe Hospital, Hubei University of Medicine, Shiyan, P.R. China; \\ ${ }^{3}$ Hubei Key Laboratory of Stem Cell Research, Taihe Hospital, Hubei University of Medicine, Shiyan, P.R. China; \\ ${ }^{4}$ Department of Surgery, University of British Columbia, Vancouver, BC, Canada
}

\begin{abstract}
Background/Aim: FAM92A1-289 is recognized as one of the newly-discovered putative oncogenes. This study was performed to reveal its oncogenic functions in human cervical carcinoma cells. Materials and Methods: The FAM92A1-289+ cell line was established with knock-in technique and selected by puromycin-resistance screening. Scratch assay, methylthiazol tetrazolium assay, colony forming assay and xenograft test were used to examine cell migration, cell proliferation, cell viability and tumor formation, respectively. Results: FAM92A1-289+ cells showed higher migration rate $(p<0.05)$, higher cell viability $(p<0.01)$, higher colony formation and tumor growth. The FAM92A1-289 protein was pulled-down by antibodies against proliferating cell nuclear antigen (PCNA) in the coimmunoprecipitation assay. Conclusion: The up-regulated expression of FAM92A1-289 could facilitate cell migration, boost cell proliferation and promote colony formation in vitro and tumor growth in vivo. The interaction between FAM92A1289 and PCNA was verified by co-immunoprecipitation. This study provided functional evidence for FAM92A1-289 to be developed as a therapeutic target for cancer treatment.
\end{abstract}

FAM92Al gene was first identified by Strausberg et al. in 2001 (1) and its full sequence was cloned and reported by

\footnotetext{
*These Authors contributed equally to this study.

Correspondence to: Xu-Zhi Ruan, College of Basic Medicine, Hubei University of Medicine, 32 South Renmin Road, Shiyan 442000, P.R. China. Tel: +86 7198891088, Fax: +86 7198891088, e-mail: ruanxuzhi@163.com and Long-Jun Dai, Department of Surgery, University of British Columbia, 400-828 West 10th Avenue, Vancouver, BC, V5Z 1L8 Canada. Tel: +1 6048754111 (Ext.62501), Fax: +16048754376, e-mail: 1jdai@mail.ubc.ca or longjundai@gmail.com
}

Key Words: FAM92A1-289, proliferation, HeLa cells, proliferating cell nuclear antigen. the Mammalian Gene Collection Program (gi:34222189) in 2004 (2). Recently, FAM92Al was considered as one of the newly discovered putative oncogenes (3). Tumor growth is closely related to cell proliferation and cell-cycle control. Hence, the regulation of tumor cell cycle by proliferationrelated genes is an important part of the research on mechanisms underlying tumorigenesis. FAM92A1 is a highly conserved gene located at $8 \mathrm{q} 22.1$ that has 10 transcriptional variants and encodes a group of small-molecule nucleoproteins (4). Expressed sequence tag analysis indicated an extensive expression of FAM92A1 in multiple stages of human development in both normal and cancer tissues. The derived amino acid sequence analysis revealed that FAM92Al is highly conserved gene in vertebrates belonging to the family of conserved DUF1208 domaincontaining proteins $(5,6)$. DUF1208 is structurally similar to the BAR domain, which has been implicated in tumorigenesis and other cellular processes (7). FAM92A1289 (GenBank Accession No. A1XBS5) is a newly-cloned transcriptional variant of FAM92Al by our previous study, that is widely expressed in multiple tissues, including many normal and tumor tissues or cells $(4,5)$. It is the largest variant of FAM92Al encoding a nucleoprotein of 289 amino acids and containing the complete DUF1208 domain. Alternative splicing is widespread in the human genome and the expression of splicing variants is highly correlated with human diseases, such as cancer (8). It has been reported that the cell growth was augmented in renal carcinoma OS-RC2 cells in vitro and in vivo upon transfection with FAM92Al289 gene (4). Therefore, FAM92A1-289 may be a novel gene related to tumor cell proliferation. To test this hypothesis in the present study, the human cervical carcinoma cells (HeLa cells) that stably express FAM92A1-289 were used to study the role of FAM92A1-289 in tumor cell proliferation. The effects of FAM92A1-289 overexpression on cell migration capacity, cell viability and tumorigenicity were investigated using in vitro and in vivo models. As a master regulator of 
DNA replication fork restart, the proliferating cell nuclear antigen ((PCNA), a nucleoprotein) plays an essential role in DNA replication, repair and cell-cycle regulation (9). Whether FAM92A1-289 protein interacts with PCNA was also examined in the current study.

\section{Materials and Methods}

Cells and animals. The human cervical carcinoma cell line (HeLa cells) was purchased from the American Type Culture Collection (ATCC, Manassas, VA, USA). The HeLa cells were cultured in Dulbecco's modified Eagle's medium (DMEM) with $10 \%$ fetal bovine serum (FBS), $2 \mathrm{mM}$ L-glutamine and $1 \%$ penicillinstreptomycin solution (all from Invitrogen, Shanghai, China) and incubated at $37^{\circ} \mathrm{C}$ in a humidified atmosphere with $5 \% \mathrm{CO}_{2}$. Subculture was performed once newly grown cells reached subconfluence. All cells used in the present study were limited in 35 passages. Nude mice (female, 4-6 weeks of age) were purchased from the Model Animal Research Center at Nanjing University (Nanjing, China) and housed in accordance with the National Institutes of Health Guide for the Care and Use of Laboratory Animals. The experimental protocols of the present study were approved by the Animal Care Committee at Hubei University of Medicine (Shiyan, China). The mice were subject to xenotransplantation of HeLa cells followed by series of imaging detection under anesthesia. Anesthesia was performed using intraperitoneal injection of pentobarbital $(90 \mathrm{mg} / \mathrm{kg}$; Shanghai Chemical Reagent, Shanghai, China).

RNA isolation from HeLa cells. Total RNA was isolated from Hela cells using TRIzol reagent (Invitrogen) as per manufacturer's instruction. RNA integrity was confirmed by electrophoresis on a $1 \%$ agarose gel. Hela cell-derived cDNA was used as the template for PCNA amplification, which was involved in the construction of expression vector.

The construction of expression vectors. The fragments of GFPFAM92A1-289 and PCNA were amplified by PCR. The PCR template for the GFP-FAM92A1-289 was pEGFP-FAM92A1-289 plasmid that was constructed in our previous study (5). The PCR primers for this fragment were 5'-CGGAATTCATGA TGAGGCG CACC-3' (forward, containing an ECoRI site) and 5'-CCGC TCGAGTTACTTGTACAGCTCGT-3' (reverse, containing an XhoI site). Hela cell-derived cDNA was used as the template for PCNA amplification and the primers for amplifying the complete coding region of PCNA were 5'-CGCCTCGAGATGTTCGAGGCGC GCCTGGT-3' (forward, containing an XhoI site) and 5'-CGGGG ATCCCTAAGATCCTTCTTCATCCT-3' (reverse, containing a $B a m \mathrm{HI}$ site). The primers used in this study were designed based on the sequences of human FAM92A1-289 and PCNA in GenBank database (accession numbers: DQ327716 and NM182649) and synthesized by Sangon Biotech (Shanghai, China). The PCR amplification was conducted at $95^{\circ} \mathrm{C}$ for $5 \mathrm{~min}$, then for 30 cycles of $95^{\circ} \mathrm{C}$ of $30 \mathrm{sec}$ each, $55^{\circ} \mathrm{C}$ for $30 \mathrm{sec}, 72^{\circ} \mathrm{C}$ for $1 \mathrm{~min}$ and, lastly, with a final extension cycle of $72^{\circ} \mathrm{C}$ for $10 \mathrm{~min}$. The amplified DNA fragments were identified by $1 \%$ agarose gel with ethidium bromide staining.

The amplified fragments of GFP-FAM92A1-289 and PCNA were inserted into the expression vector CMV-SP6-TALEN (SIDANSAI) with puromycin-resistance gene and the pcDNA3.1(-) vector. Briefly, the target fragments were purified with universal DNA purification/recovery kit (Tiangen, Beijing, China). Then, both the amplified DNA fragments and the vector were doubly digested with endonucleases, correspondingly. The target fragments and the target vector backbone were extracted from the gel using universal DNA purification/recovery kit and then they were ligated overnight at $16^{\circ} \mathrm{C}$. The ligation products were transfected into competent $E$. coli cells DH5 $\alpha$ and screened with LB plate for $16 \mathrm{~h}$ at $37^{\circ} \mathrm{C}$. The obtained recombinant plasmids were extracted with a DNA miniextraction kit (Sigma, St. Louis, MO, USA) and confirmed by DNA sequencing and restriction enzyme digestion (Takara, Dalian, China).

Optimal puromycin concentration for the screening of HeLa cell line. Since the CMV-SP6-TALEN vector contained a puromycinresistance gene, the optimal puromycin concentration was determined for screening purpose. The HeLa cells in logarithmic phase were cultured in 24-well plates with the same density of $5 \times 10^{4}$ cells/well. When the cells reached $80 \%$ confluency, puromycin was added into the culture medium for screening. The concentrations of puromycin solutions were set as $0.25,0.5,0.75$, $1,1.5,2$ and $3 \mu \mathrm{g} / \mathrm{ml}$. Triplicate tests were performed for each concentration. After 9 days of culture, all Hela cells cultured with $1.5,2$ and $3 \mu \mathrm{g} / \mathrm{ml}$ puromycin solution died. Therefore, the concentration of $1.5 \mu \mathrm{g} / \mathrm{ml}$ was considered as optimal puromycin concentration for screening HeLa cells.

Screening of stably transfected cell line and target protein identification. HeLa cells were cultured till $80 \%$ confluency and then transfected with the CMV-SP6-TALEN-GFP-289 vector using Lipofectamine $^{\mathrm{TM}} 2000$ transfection reagent (Invitrogen) as per manufacturer's instruction. After $24 \mathrm{~h}$ of incubation, the transfection medium was replaced with fresh medium containing $1.5 \mu \mathrm{g} / \mathrm{ml}$ puromycin to initiate positive HeLa cell screening procedure. The same culture medium was replaced every third day for 9 days. On day 10 , the HeLa cells transfected with CMV-SP6-TALEN-GFP289 (HeLa/GFP-289) showed good growth and were observed under a microscope to confirm the presence of green fluorescence.

Sodium dodecyl sulfate-polyacrylamide gel electrophoresis (SDS-PAGE) was used to identify the expression of target protein, i.e. GFP-FAM92A1-289. Briefly, HeLa/GFP-289, HeLa /PEGFP$\mathrm{N} 1$ (positive control) and wild type HeLa cells (negative control) were cultured in 6-well plates. Cells of each group were collected in $1.5 \mathrm{ml}$ microcentrifuge tubes, washed twice with ice-cold PBS and lysed in $100 \mu \mathrm{l}$ cell lysis buffer (Beyotime, Jiangsu, China) containing $1 \mathrm{mM}$ phenymethylsulfonyl fluoride (PMSF). Samples were chilled on ice for $30 \mathrm{~min}$ and then centrifuged at $10,000 \mathrm{x} \mathrm{g}$ at $4^{\circ} \mathrm{C}$ for $5 \mathrm{~min}$. The supernatant was re-suspended in $6 \mathrm{X}$ sample buffer and boiled for 5 minutes.

Protein samples $(30 \mu \mathrm{g})$ were electrophoresed in SDS-PAGE and transferred onto nitrocellulose membrane. The membrane was blocked with $5 \%$ bovine serum albumin (BSA) for $1 \mathrm{~h}$ at room temperature followed by an overnight incubation with primary antibody against GFP (1:500; Santa Cruz Biotechnology, Santa Cruz, CA, USA) at $4^{\circ} \mathrm{C}$. After washing three times with Trisbuffered saline, $0.1 \%$ Tween 20 (TBST), the membrane was incubated with alkaline phosphatase-conjugated secondary antibody (1:500; Beyotime) for $1 \mathrm{~h}$ at room temperature. The membrane was washed three times with TBST and imaged with a gel imaging system (Bio-Rad Laboratories, Hercules, CA, USA). 
Scratch assay. The scratch assay was used to detect the effects of FAM92A1-289 on cell migration capability. HeLa/GFP-289 and wild type HeLa cells were cultured in 6 -well plates $\left(1 \times 10^{5}\right.$ cells/well). When the cells reached complete confluency, a line was scratched in the middle of the wells using a $200-\mu$ l pipette tip. The plates were washed with PBS for three times. Cells were then incubated with fresh serum-free DMEM medium at $37^{\circ} \mathrm{C}$ with $5 \%$ $\mathrm{CO}_{2}$ for $48 \mathrm{~h}$. As described in a previous study (10), the width of scratched line was measured and the percentage of narrow down was compared at $0 \mathrm{~h}, 24 \mathrm{~h}$ and $48 \mathrm{~h}$, respectively. The experiment was performed in triplicates.

MTT assay. Cell viability was evaluated using the MTT assay as previously described (11). HeLa cells and HeLa/GFP-289 cells were seeded into 96 -well microplate at a density of $2.5 \times 10^{3}$ cells/well. Five replicates were set for each type of the cells. On days 1, 3, 5 and 7 after incubation, $20 \mu \mathrm{l}$ methylthiazol tetrazolium ((MTT), $5 \mathrm{mg} / \mathrm{ml}$; Beyotime) was added to each well followed by $4 \mathrm{~h}$ incubation. Then, $100 \mu \mathrm{l}$ formazan solution was added to dissolve the crystal violet. The optical absorbance at wavelength $570 \mathrm{~nm}$ (A570) was recorded with a Vmax Microplate reader (Thermo Scientific, Waltham, MA, USA). The value of A570 is proportional to the number of viable cells in each well.

Colony forming ability assay. The HeLa cells and HeLa/GFP-289 cells in good growth condition were counted and $1 \times 10^{3}$ cells were plated into a 12 -well plate pre-coated with $1 \%$ gelatin. The cells were cultured with serum-free DMEM/F12 medium (containing $100 \mathrm{U} / \mathrm{ml}$ penicillin, $100 \mu \mathrm{g} / \mathrm{ml}$ streptomycin, $20 \mathrm{ng} / \mathrm{ml}$ epidermal growth factor (EGF), $10 \mathrm{ng} / \mathrm{ml}$ basic fibroblast growth factor (bFGF)) at $37^{\circ} \mathrm{C}$ for $10-14$ days. Three replicates were set for each type of the cells. The culture medium was replaced according to the cell growth rate and the color changes of the culture medium. The cultures were photographed regularly under the microscope to observe colony formation.

Xenograft test. Since the In Vivo Imaging System (IVIS) is preferentially sensitive to bioluminescence, luciferase genetransfected HeLa cells (HeLa-luc cells) were used for the xenograft test, including HeLa-luc cells and FAM92A1-289-transfected HeLaluc cells. The cells were harvested when they reached logarithmic phase of growth. Then, $1 \times 10^{7}$ of these cells were subcutaneously injected from the right of the inguinal region of nude female mouse (5 mice each group). All the xenografted animals were imaged every week using a small animal image system (IVIS; Caliper Life Sciences, Hopkinton, MA, USA) until the mice died. Each test was conducted 10 minutes after an anesthetized mouse received $200 \mu 1$ D-luciferin solution $(0.15 \mathrm{mg} / \mathrm{ml}$, Caliper Life Sciences $)$ intraperitoneal injection. The growth rate and size of tumors were analyzed using the radiance value, which is proportional to the number of bioluminescence-producing cells (10).

Co-immunoprecipitation assay. Because HeLa cells express PCNA, it is an ideal cell model to study protein interaction between FAM92A1-289 and PCNA. However, the content of endogenous PCNA is too low to perform co-immunoprecipitation assay; therefore, pcDNA3.1-PCNA plasmid was transfected into HeLa cells to enhance the expression of PCNA. After pcDNA3.1-PCNA was transfected into $\mathrm{HeLa} / \mathrm{GFP}-289$ cells, these cells could overexpress both GFP-FAM92A1-289 and PCNA simultaneously.
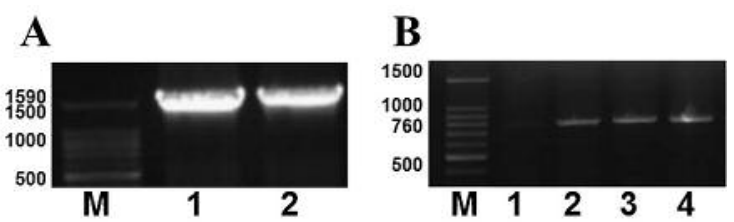

Figure 1. Gel electrophoresis of FAM92A1-289 gene PCR products. The $P C R$ products of GFP-FAM92A1-289 gene (A) and PCNA gene (B) were isolated by $1 \%$ agarose gel. M: DNA ladders.

The protein sample extracted from the double transfected HeLa cells was used for co-immunoprecipitation assay. Sufficient amount of PCNA antibody was added into $200 \mu \mathrm{g}$ total protein sample and gently rotated at $4^{\circ} \mathrm{C}$ overnight. To pull down PCNA antibodies, protein sample was incubated with $40 \mu \mathrm{l}$ protein $\mathrm{A} / \mathrm{G}$ Agarose beads (Beyotime) for an additional $3 \mathrm{~h}$ period at $4^{\circ} \mathrm{C}$. The precipitate was washed for five times with ice-cold radioimmunoprecipitation assay (RIPA) buffer and re-suspended in $1 \mathrm{X}$ sample buffer followed by boiling for 5 minutes to dissociate the immunocomplex from the beads. The supernatant was collected by centrifugation and subjected to Western blot. The protein of coimmunoprecipitation was detected by antibodies against GFP and PCNA in order to observe whether GFP-289 and PCNA coexisted in the precipitation.

Statistical analysis. Numerical data were presented as the mean \pm deviation (SD). $\chi^{2}$ test was used to compare the rate of two samples. Statistical analyses were performed with the $t$-test by using SPSS 13.0 (SPSS Inc., Chicago, IL, USA) and $p<0.05$ was considered statistically significant.

\section{Results}

Detection of recombinant vectors CMV-SP6-TALEN -GFP289 and pcDNA3.1-PCNA. The recombinant vectors CMVSP6-TALEN-GFP-289 and pcDNA3.1-PCNA were digested with restriction enzymes and the target fragments were obtained (Figure 1). The result of $1 \%$ agarose gel electrophoresis showed bands at the positions of 1,590 bp and $786 \mathrm{bp}$, respectively, which were the same sizes as expected. The products were submitted for sequencing by Sangon Biotech (Shanghai) and the sequencing results showed neither base insertion nor deletion.

Assessment of FAM92A1-289-overexpressing HeLa cells (HeLa/GFP-289 cells). As shown in Figure 2A, a 61-KDa protein was detected in cells overexpressing FAM92A1-289, whereas a 27-KDa protein was found in HeLa/ GFP-N1 cells (HeLa/GFP-N1 as control group). Moreover, the HeLa/GFP289 cells showed strong green fluorescence and presented good growth condition (Figure 2B). Together, these data demonstrated that the FAM92A1-289 stably-transfected cell line was successfully established. 


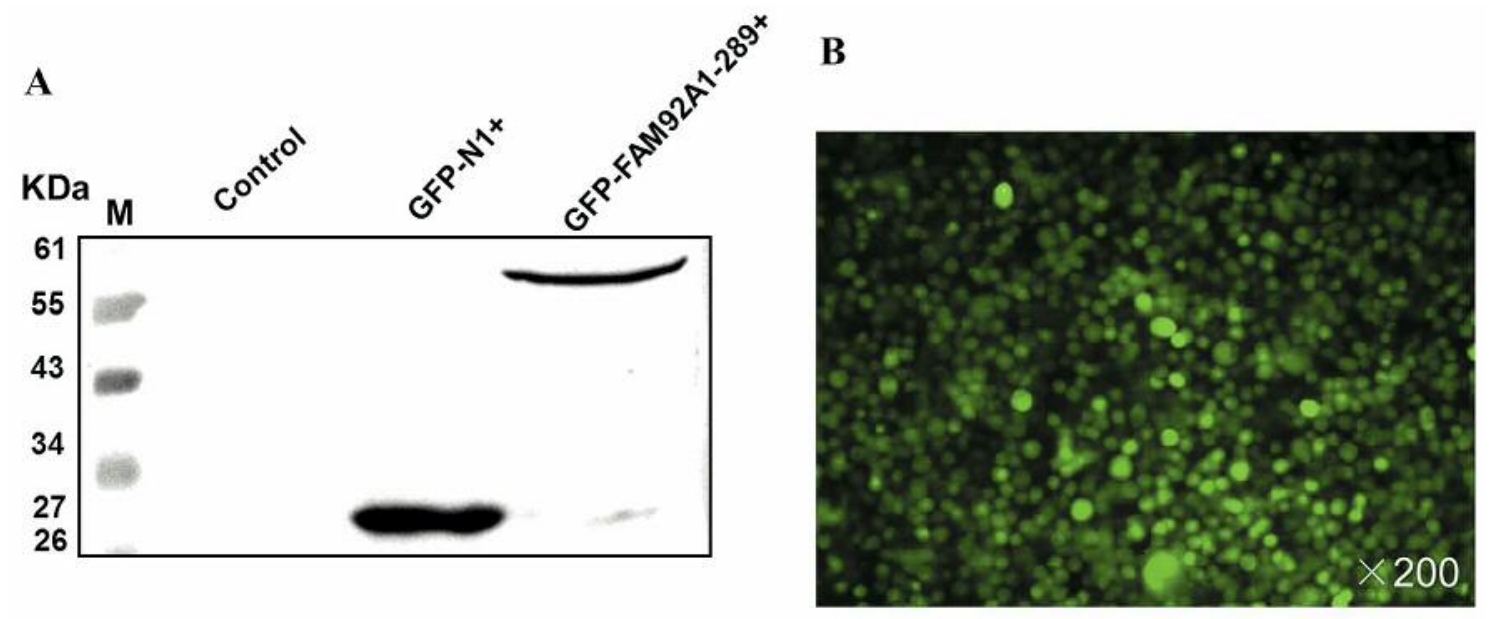

Figure 2. Detection of FAM92A1-289 expression in HeLa cells. (A) Western blot analysis of FAM92A1-289 expression. Protein extractions from wild-type HeLa cells (control), GFP-N1-transfected HeLa cells (GFP-N1+) and HeLa/GFP-289 cells (GFP-FAM92A1-289+) were separated by SDS-PAGE and detected by GFP monoclonal antibodies. M: Protein molecular weight markers. (B) A representative image of HeLa/GFP-289 cells under fluorescence microscope.

A

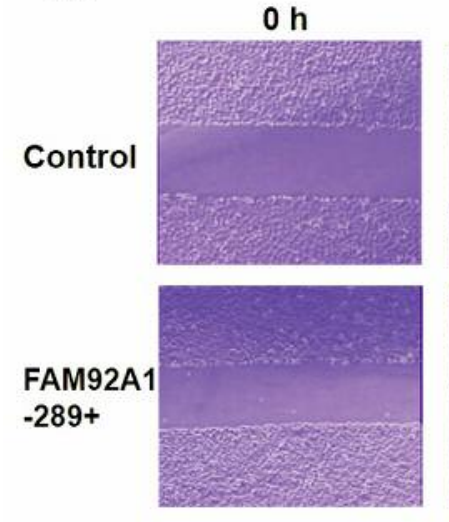

$24 \mathrm{~h}$
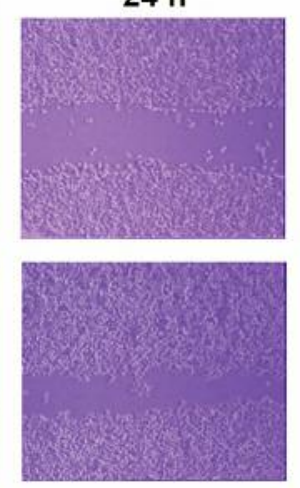

$48 \mathrm{~h}$

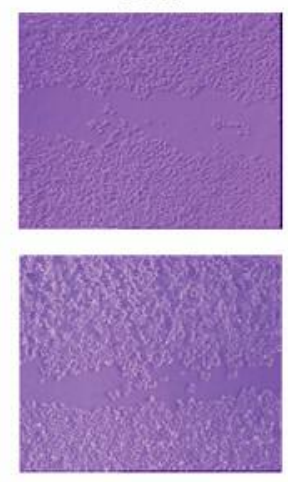

B

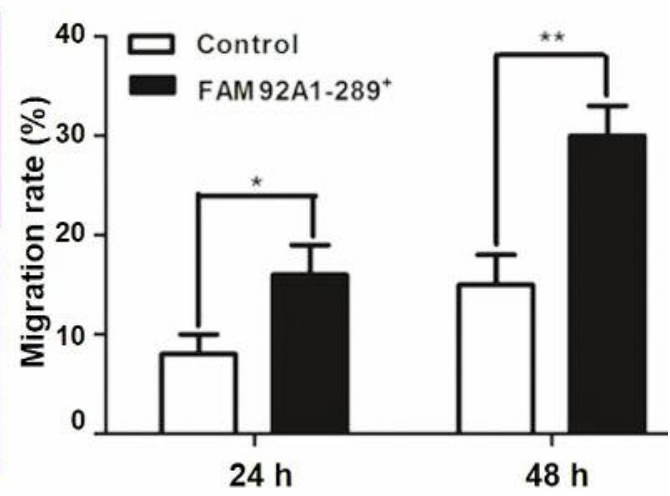

Figure 3. The effect of FAM92A1-289 on migrating capacity in HeLa cells. (A) Scratch assay of wild-type HeLa cells (Control) and HeLa/GFP-289 cells $($ FAM92A1-289+). The representative pictures were taken at $0 \mathrm{~h}, 24 \mathrm{~h}$ and $48 \mathrm{~h}$ after scratching. (B) Comparison of migration rate between wild-type HeLa cells (Control) and HeLa/GFP-289 cells $\left(F A M 92 A 1-289^{+}\right)$at $24 \mathrm{~h}$ and $48 \mathrm{~h}$. The differences were significant both at $24 \mathrm{~h}(* p<0.05)$ and at $48 h(* *<<0.05)$.

FAM92A1-289 facilitates the migration capacity of HeLa cells. As shown in Figure 3A and 3B, the migration rates of $\mathrm{HeLa} / \mathrm{GFP}-289$ cells at 24 and $48 \mathrm{~h}$ were $16 \pm 4 \%$ and $27 \pm 4 \%$, respectively, while those of wild HeLa cells (control) were $8 \pm 3 \%$ and $16 \pm 3 \%(p<0.05)$.

FAM92A1-289 boosts the proliferation of HeLa cell. Figure 4 shows the survival and growth rate of HeLa/GFP-289 cells and that of wild-type HeLa cells (control). The MTT value in the FAM92A1-289 overexpression groups were significantly higher than that in the control groups at all tested time points $(p<0.05$ and $p<0.01)$. The results suggested that FAM92A1-289 was involved in cell growth.

FAM92A1-289 promotes colony formation in vitro and tumor growth in vivo. In the colony-forming assay, tumor spheres appeared in both groups on day 3 . The tumor spheres became bigger and rounded on day 5 . The cells were photographed under the inverted microscope on days 3,5 and 10 , respectively. As shown in Figure 5A and 5B, HeLa/GFP-289 cell-derived tumor spheres were much bigger, denser and more numerous at all detected time points compared to 


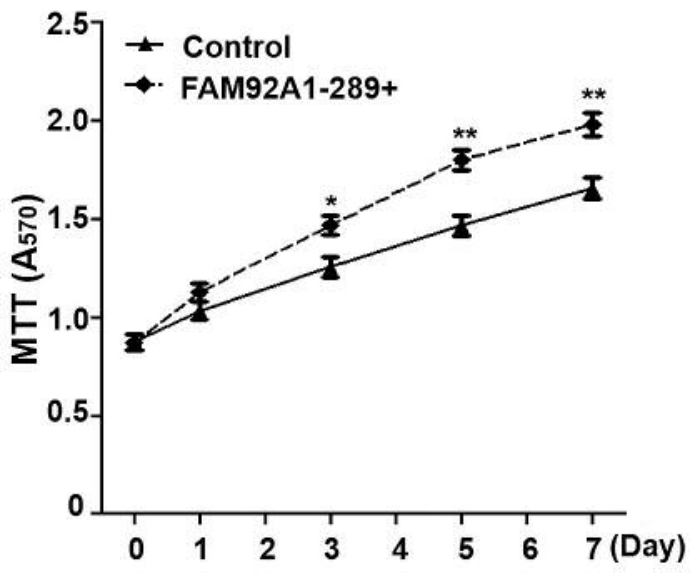

Figure 4. The effect of FAM92A1-289 on cell viability in HeLa cells. The MTT values were measured on the days 1, 3, 5 and 7 after cell inoculation. Control stands for the wild-type HeLa cells; FAM92A1$289^{+}$stands for the HeLa/GFP-289 cells. Results show mean $\pm S D(n=6)$. ${ }^{*} p<0.05, * * p<0.01$, versus control.

control HeLa cell-derived tumor spheres. It was also found that the proliferation capacity of HeLa/GFP-289 cells was higher than control cells, indicating FAM92A1-289's role in promoting the proliferation of HeLa cells.

In order to directly assess the effect of FAM92A1-289 on tumorigenesis, HeLa/GFP-289 and HeLa-luc cells were subcutaneously xenotranplanted into nude mice. The size of neoplasms was measured weekly with an in vivo imaging system until mice died. We found that the difference in tumor volume was observed after 14 days of inoculation of HeLa cells. The volumes of HeLa/GFP-289 cell-derived tumors were significantly larger than that control HeLa cells on day 28. Furthermore, mice inoculated with HeLa/GFP289 cells died earlier than those with control HeLa cells (Figure 5C and 5D). These results suggest that FAM92A1289 promotes the proliferation of HeLa cells.

FAM92A1-289 interacts with PCNA. Western blotting (Figure 6) showed that the $36 \mathrm{KDa}$ PCNA proteins were detected in the HeLa cells' extraction solution, whereas much stronger expression in the HeLa cells transfected with pcDNA3.1PCNA was revealed. On the contrary, both $36 \mathrm{KDa}$ PCNA and $61 \mathrm{KDa}$ GFP proteins were detected in the immunoprecipitate. These data suggest that the GFP-289 proteins were pulled down by PCNA antibodies suggesting that FAM92A1-289 can interact with PCNA to form a multi-protein complex.

\section{Discussion}

Cancer is caused by genomic alterations that occur in oncogenes, tumor suppressor genes and microRNA genes (12). The majority of oncogene proteins function as elements of the signaling pathways that regulate cell proliferation and survival. Since "oncogene theory" was first proposed by Huebner and Todaro in 1969 (13), a few hundreds of oncogenes have been identified, including viral and cellular oncogenes that contribute to the uncontrolled proliferation of cancer cells. The relevance of FAM92A1-289 to cancer cell proliferation was first revealed by Liang et al. in 2009 (4). In the present study, a detailed functional study of FAM92A1289 was conducted using stably transfected HeLa cells.

The use of a stably-transfected cell line is a useful method to study the functions of genes, thus providing clear benefits to researchers concerning the repeatability and reliability of the undertaken experiments. The eukaryotic expression vector CMV-SP6-TALEN-GFP-289 constructed contained both the FAM92A1-289 gene and puromycin resistance gene. This structure was verified by sequencing and restriction enzyme digestion (Figure 1). The stably-transfected HeLa/289 cell line was successfully established through screening process. HeLa/289 cells overexpressed FAM92A1-289 and emitted green fluorescence, which was confirmed by fluorescence microscopy and Western blot analysis (Figure 2).

Cell migration plays an important part in tumor metastasis. In vitro scratch assay is a well-developed and easy method for analyzing cell migration in vitro (14). Upregulated expression of FAM92A1-289 could promote the migration capacity of HeLa cells (Figure 3). Actually, the observed changes of migration capacity were also attributed to FAM92A1-289-induced enhancement of cell viability. This viewpoint was evidenced by the MTT assay in the study. MTT assay has been widely used to detect cell viability in vitro (15). The viability of HeLa cells was significantly enhanced by FAM92A1-289 overexpression (Figure 4). Colony forming property of tumor cells is an essential factor during tumorigenesis $(16,17)$. The in vitro colony forming assay was used to explore the effects of FAM92A1-289 on colony forming capacity in HeLa cells. HeLa/GFP-289 cells (overexpressing FAM92A1-289) cultured in semisolid media showed much higher colony forming capacity than wild type HeLa cells. As demonstrated in Figure 5, FAM92A1-289-induced reinforcement of colony forming capacity was further evidenced by in vivo tumorigenesis experiment. Compared with wild type HeLa cell-derived tumors, HeLa/GFP-289 cell-derived tumors grew much faster and the tumor-bearing animals survived considerably less, thereby indicating the oncogenic effect of FAM92A1-289.

FAM92A1-289 holds a great potential to be a therapeutic target for cancer treatment. It is critical to explore the mechanisms underlying its antitumor effects, as well as possible signal pathways. FAM92A1-289 belongs to the family of conserved DUF1208 domain-containing proteins structurally similar to the BAR domain. It has been reported that this family of proteins is implicated in diverse 

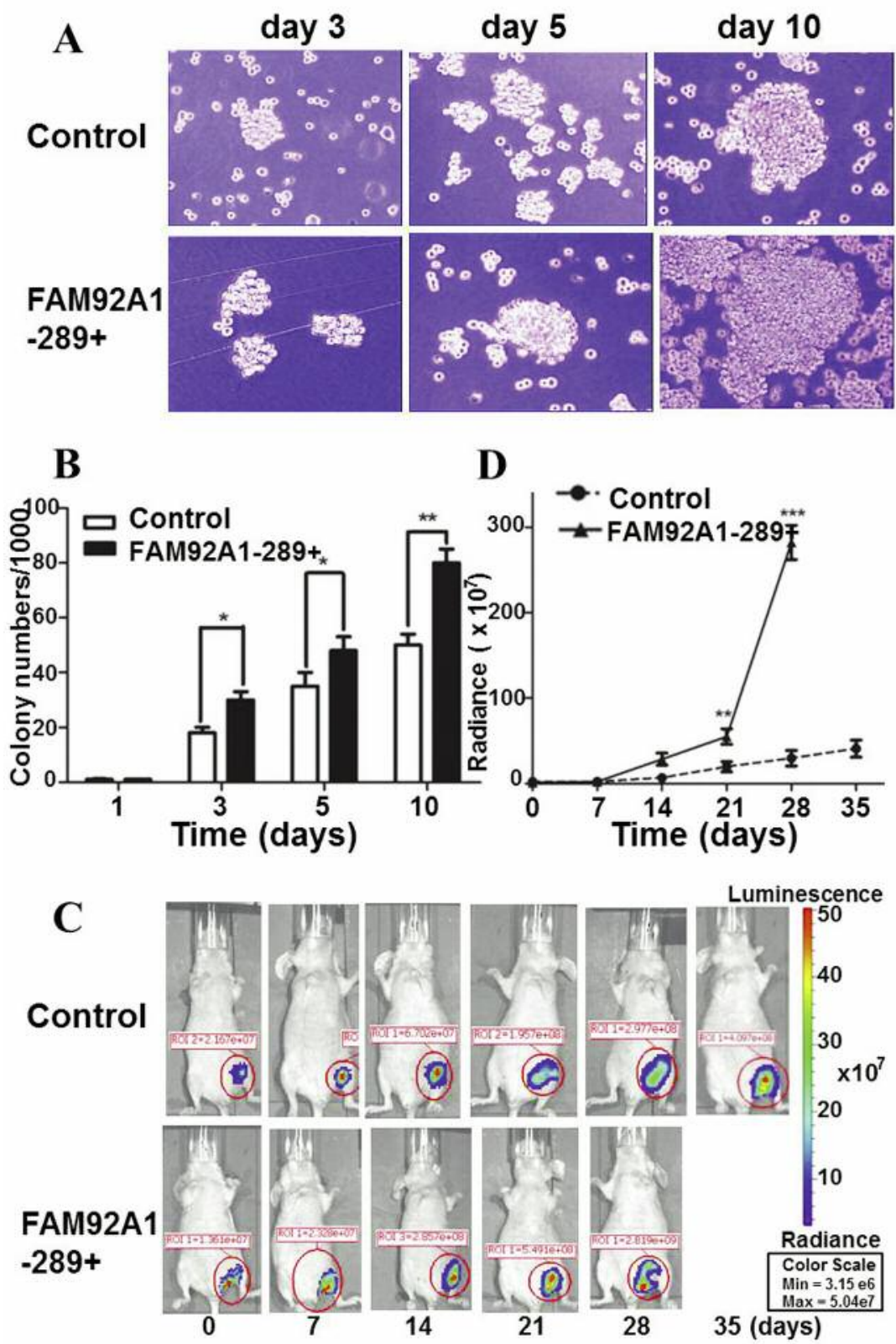

Figure 5. The effects of FAM92A1-289 on colony formation in vitro and tumor growth in vivo. (A) The in vitro colony formation in cultured HeLa cells (control) and the HeLa /GFP-289 cells. Images were taken on days 3, 5 and 10 under an inverted microscope. (B) Summary of colony-forming assay. Results show mean $\pm S D(n=5)$. ${ }^{*} p<0.05, * * p<0.01$, compared to control. $(C)$ The in vivo observation of xenografts derived from HeLa (Control) and HeLa /GFP-289 cells using a small animal imaging system. Whole animal images were taken every week until the mice died. Radiance value was used to represent the amount of bioluminescence-producing cells or tumor volume. (D) Time course of xenografted tumor growth. Results show mean $\pm S D(n=5) . * * p<0.01, * * * p<0.001$, compared to control.

cellular processes, including differentiation, cell survival and tumorigenesis (7). Additionally, the DUF1208 domaincontaining proteins contain several PKC phosphorylation sites, N-myristoylation sites and a coiled-coil domain (6). The coiled-coil domains are highly versatile protein folding motifs and actively involved in protein-protein interactions
(18). Co-immunoprecipitation is a useful technique for evaluating protein-protein interactions (19). Here, it was used to verify whether FAM92A1-289 protein interacts with PCNA, a master regulator of DNA replication and cell proliferation. Because there is no antibody for FAM92A1289 at present, GFP-FAM92A1-289 was detected using 


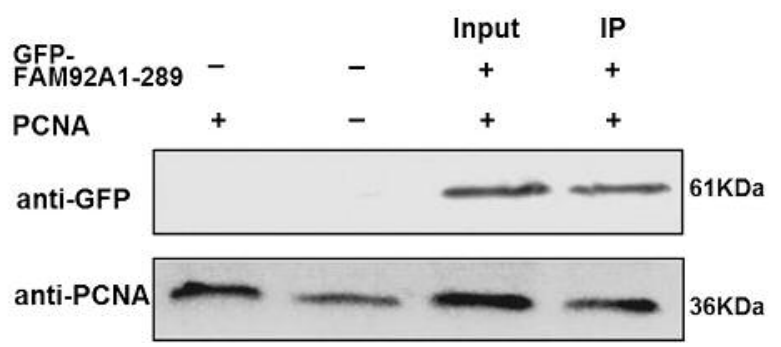

Figure 6. Co-immunoprecipitation of FAM92A1-289 and PCNA. Lane 1: Extraction solution of HeLa cells transfected with pcDNA3.1-PCNA; Lane 2: Extraction solution of wild-type HeLa cells; Lane 3: Protein of HeLa cells that overexpressed PCNA and FAM92A1-289; Lane 4: The co-immunoprecipitation complexes of PCNA and FAM92A1-289. The proteins were detected by GFP and PCNA antibodies as indicated in the left side of the figure.

anti-GFP antibody. The data showed that FAM92A1-289 could interact with PCNA (Figure 6). However, further studies are definitely required to elucidate the potential related molecular mechanisms underlying the interaction of these proteins.

In conclusion, FAM92A1-289 retains many oncogenic properties evidenced by facilitating cell migration, boosting cell proliferation and promoting colony formation in vitro and tumor growth in vivo. The results of coimmunoprecipitation assay suggested that FAM92A1-289 could interact with PCNA. This study provided functional evidence for FAM92A1-289 to be developed as a therapeutic target for cancer treatment.

\section{Acknowledgements}

This study was supported by Hubei Science and Technology Foundation (NO.2012FFB02001). The Authors would like to thank Jing-Bo Feng (Hubei Key Laboratory of Stem Cell Research, Taihe Hospital, Hubei University of Medicine, Shiyan, China) for technical assistance.

\section{References}

1 Strausberg RL, Feingold EA, Grouse LH, Derge JG, Klausner RD, Collins FS, Wagner L, Shenmen CM, Schuler GD, Altschul SF, Zeeberg B, Buetow KH, Schaefer CF, Bhat NK, Hopkins RF, Jordan H, Moore T, Max SI, Wang J, Hsieh F, Diatchenko L, Marusina K, Farmer AA, Rubin GM, Hong L, Stapleton M, Soares MB, Bonaldo MF, Casavant TL, Scheetz TE, Brownstein MJ, Usdin TB, Toshiyuki S, Carninci P, Prange C, Raha SS, Loquellano NA, Peters GJ, Abramson RD, Mullahy SJ, Bosak SA, McEwan PJ, McKernan KJ, Malek JA, Gunaratne PH, Richards S, Worley KC, Hale S, Garcia AM, Gay LJ, Hulyk SW, Villalon DK, Muzny DM, Sodergren EJ, Lu X, Gibbs RA, Fahey J, Helton E, Ketteman M, Madan A, Rodrigues S, Sanchez A, Whiting M, Madan A, Young AC, Shevchenko Y, Bouffard GG, Blakesley RW, Touchman JW, Green ED, Dickson MC,
Rodriguez AC, Grimwood J, Schmutz J and Myers RM: Generation and initial analysis of more than 15,000 full-length human and mouse cDNA sequences. Proc Natl Acad Sci USA 99: 16899-16903, 2002.

2 Ota T, Suzuki Y, Nishikawa T, Otsuki T, Sugiyama T, Irie R, Wakamatsu A, Hayashi K, Sato H, Nagai K, Kimura K, Makita H, Sekine M, Obayashi M, Nishi T, Shibahara T, Tanaka T, Ishii S, Yamamoto J, Saito K, Kawai Y, Isono Y, Nakamura Y, Nagahari K, Murakami K, Yasuda T, Iwayanagi T, Wagatsuma M, Shiratori A, Sudo H, Hosoiri T, Kaku Y, Kodaira H, Kondo H, Sugawara M, Takahashi M, Kanda K, Yokoi T, Furuya T, Kikkawa E, Omura Y, Abe K, Kamihara K, Katsuta N, Sato K, Tanikawa M, Yamazaki M, Ninomiya K, Ishibashi T, Yamashita H, Murakawa K, Fujimori K, Tanai H, Kimata M, Watanabe M, Hiraoka S, Chiba Y, Ishida S, Ono Y, Takiguchi S, Watanabe S, Yosida M, Hotuta T, Kusano J, Kanehori K, Takahashi-Fujii A, Hara H, Tanase TO, Nomura Y, Togiya S, Komai F, Hara R, Takeuchi K, Arita M, Imose N, Musashino K, Yuuki H, Oshima A, Sasaki N, Aotsuka S, Yoshikawa Y, Matsunawa H, Ichihara T, Shiohata N, Sano S, Moriya S, Momiyama H, Satoh N, Takami S, Terashima Y, Suzuki O, Nakagawa S, Senoh A, Mizoguchi H, Goto Y, Shimizu F, Wakebe H, Hishigaki H, Watanabe T, Sugiyama A, Takemoto M, Kawakami B, Yamazaki M, Watanabe K, Kumagai A, Itakura S, Fukuzumi Y, Fujimori Y, Komiyama M, Tashiro H, Tanigami A, Fujiwara T, Ono T, Yamada K, Fujii Y, Ozaki K, Hirao M, Ohmori Y, Kawabata A, Hikiji T, Kobatake N, Inagaki H, Ikema Y, Okamoto S, Okitani R, Kawakami T, Noguchi S, Itoh T, Shigeta K, Senba T, Matsumura K, Nakajima Y, Mizuno T, Morinaga M, Sasaki M, Togashi T, Oyama M, Hata H, Watanabe M, Komatsu T, Mizushima-Sugano J, Satoh T, Shirai Y, Takahashi Y, Nakagawa K, Okumura K, Nagase T, Nomura N, Kikuchi H, Masuho Y, Yamashita R, Nakai K, Yada T, Nakamura Y, Ohara O, Isogai T and Sugano S: Complete sequencing and characterization of 21,243 full-length human cDNAs. Nat Genet 36: 40-45, 2004.

3 Marcucci G, Yan P, Maharry K, Frankhouser D, Nicolet D, Metzeler KH, Kohlschmidt J, Mrozek K, Wu YZ, Bucci D, Curfman JP, Whitman SP, Eisfeld AK, Mendler JH, Schwind S, Becker H, Bär C, Carroll AJ, Baer MR, Wetzler M, Carter TH, Powell BL, Kolitz JE, Byrd JC, Plass C, Garzon R, Caligiuri MA, Stone RM, Volinia S, Bundschuh R and Bloomfield CD: Epigenetics meets genetics in acute myeloid leukemia: clinical impact of a novel seven-gene score. J Clin Oncol 32: 548-556, 2014.

4 Liang S, Gong F, Zhao X, Wang X, Shen G, Xu Y, Yang H, Ruan $\mathrm{X}$ and Wei Y: Prokaryotic expression, purification of a new tumor-relative protein FAM92A1-289 and its characterization in renal cell carcinoma. Cancer Lett 276: 81-87, 2009.

5 Ruan XZ, Yan F, Zhao XY, Wang CT, Song M, Yang HS, Deng $\mathrm{HX}$ and Wei YQ: Identification and characterization of two novel variants of the DUF1208 protein FAM92A1. Mol Cells 23: 391-397, 2007.

6 Ruan XZ, Yang HS, Yao SH, Ma FX, Zhao XY, Yan F, Wang CT, Lai ST, Deng HX and Wei YQ: Isolation and characterization of a novel Xenopus gene (xVAP019) encoding a DUF1208 domain containing protein. Mol Reprod Dev 74: 1505-1513, 2007.

7 Peter BJ, Kent HM, Mills IG, Vallis Y, Butler PJ, Evans PR and McMahon HT: BAR domains as sensors of membrane curvature: The amphiphysin BAR structure. Science 303: 495-499, 2004. 
8. Roy M, Xu Q and Lee C: Evidence that public database records for many cancer-associated genes reflect a splice form found in tumors and lack normal splice forms. Nucleic Acids Res 33: 5026-5033, 2005

9 Choe KN, Nicolae CM, Constantin D, Imamura Kawasawa Y, Delgado-Diaz MR, De S, Freire R, Smits VA and Moldovan GL: HUWE1 interacts with PCNA to alleviate replication stress. EMBO Rep 17: 874-886, 2016.

10 Ding Y, Yu AQ, Li CL, Fang J, Zeng Y and Li DS: TALENmediated Nanog disruption results in less invasiveness, more chemosensitivity and reversal of EMT in Hela cells. Oncotarget 5: 8393-8401, 2014.

11 Tang XJ, Lu JT, Tu HJ, Huang KM, Fu R, Cao G, Huang M, Cheng LH, Dai LJ and Zhang L: TRAIL-engineered bone marrow-derived mesenchymal stem cells: TRAIL expression and cytotoxic effects on C6 glioma cells. Anticancer Res 34: 729734, 2014.

12 Croce CM: Oncogenes and cancer. N Engl J Med 358: 502-511, 2008.

13 Huebner RJ and Todaro GJ: Oncogenes of RNA tumor viruses as determinants of cancer. Proc Natl Acad Sci USA 64: 10871094, 1969.

14 Liang CC, Park AY and Guan JL: In vitro scratch assay: A convenient and inexpensive method for analysis of cell migration in vitro. Nat Protoc 2: 329-333, 2007.
15 Freire V, Andollo N, Etxebarria J, Duran JA and Morales MC: In vitro effects of three blood derivatives on human corneal epithelial cells. Invest Ophthalmol Vis Sci 53: 5571-5578, 2012.

16 von Hoff DD: Human tumor cloning assays: Applications in clinical oncology and new antineoplastic agent development. Cancer Metastasis Rev 7: 357-371, 1988.

17 Scholz CC, Berger DP, Winterhalter BR, Henss H and Fiebig $\mathrm{HH}$ : Correlation of drug response in patients and in the clonogenic assay with solid human tumour xenografts. Eur J Cancer 26: 901-905, 1990.

18 Burkhard P, Stetefeld J and Strelkov SV: Coiled coils: A highly versatile protein folding motif. Trends Cell Biol 11: 82-88, 2001.

19 Poetz O, Luckert K, Herget T and Joos TO: Microsphere-based co-immunoprecipitation in multiplex. Anal Biochem 395: 244248, 2009.
Received September 10, 2016

Revised September 20, 2016

Accepted September 21, 2016 